\title{
Notas sobre el desarrollo del. capitalismo periférico
}

\section{DOS GRANDES MITOS DEL CAPITALISMO IDERIFERICO}

El asunto sobre el que se me ha sugerido diseptar es muy vasto. Pero Felipe Herrera, siempre fértil en soluciones, me aconsejó ocuparme cle aquellos temas sobre los cuales he venido escribiendo'.

Se trata de la crítica al capitalismo imitativo de los países en desarrollo que constituyen la periferia de la economía mundial, en contraste con el capitalismo innovador de los centros industriales.

iY al plantear así el tema, surge en seguicla una gran interrogante: ¿Para qué se tha venido Iuchando de tiempo atrás en favor de un nuevo orden económico mundial? ¿Para contribuir a exaltar el capitalismo periférico o para cooperar con los países que se propongan transformar el sistema?

Me encuentro resucltamente entre los que piensan lo segundo. Me ha tocado en suerte participar en esa lucha. $Y$ en mis informes a los gobiernos, especialmente en UNCTAN, como antes en la: CEPAL, he subrayado la necesidad de esas transformaciones periféricas. Lo hice por convicción y honestidad intelectual, aun sabiendo que muy pocos gobiernos estarian dispuestos a mirar clesde esta óptica, los grandes problemas de la cooperación internacional. IP'ero había 'que comenzar.

Se viene repitiendo con mur comprensible insistencia que las disparidades económicas entre el Norte y el Sur han venido creciendo en vez de estrecharse. Pero también ha sucedido lo mismo en el seno de los países periféricos, con muy pocas excepciones. Estoy perstadido que no podrán corregirse estas graves disparidades internas por más que los países del Norte se decidan a iniciar la ejecución cle las medidas conducentes a un Nuevo Orden Económico Inter. nacional. Porque es imprescindible también un nuevo orden econó-

'Las ideas de este articulo reflejan en cierto modo lo que expresé en mi trabajo "Cirtica al capitalismo periférico" publicado en el No 1 de la Revista de la cEPA, Primer semestre de 1976 , y en. un segundo trabajo que se publicará en el No 6 Le esta Revista (segundo semestre de 1978). También contiene algunas ideas preliminares acerca de la Teoría de la Transformación que espero publicar próximamente.

Trabajo presentado en el Seminario sobre Nuevo Orden Económico Internacional y Valores Culturales, organizado por el Instituto Intercontinental de Cooperación, Madrid, en julio de 1978, y reproducido con autorización del autor. 
mico interno en los países en desarrollo, inspirado en un claro sentido social. Un Nuevo Orden que permita conseguir lo que no se ha logrado con el tipo de desarrollo prevaleciente en la América Latina, it la que circunscribiré mi exposición.

Se tha disipado en verdad el mito que alentaba las esperanzas de desarrollo hace algunos decenios. Doble mito, si se quiere. Pues dominaba la creencia de que el desarrollo traería consigo la equidad social, y que con ello se abriría paso al proceso de democratización.

No tha habido tal equidad ni tenclencia a conseguirla, aun en países que alcanzaron tasas elevadas de crecimiento. $Y$ las ilusiones de avance democrático están sufriendo tremendos contrastes. Trátase de farlas fundamentales dèl sistema.

Una de las más grandes conquistas de la cultura occidental ha llegado a comprometerse seriamente en la Amér ca Latina. Que hay inmadurez polıtica, nadie podría negarlo. Pero el problema es mucho más hondo, pues tiene sus raíces en una estructura sociaı que tiende a llevar a la democracia a devorarse a sí misma en el curso del desarrollo. $Y$ naufragan con ello los dereaios humanos antes de haber llegado su vigencia efectiva a las grandes masas de la población que han quedado excludas de los frutos del desarrollo.

Para quienes viven angustiados en nuestros pases, bajo el peso de estas calamidades, es reconfortante tener el eco de man.festaciones de solidaridad humana en ios países industriales. Pero mucho me temo que estas laudables actitudes no significan necesariamente una clara comprensión de la profundidad de los males del sistema. No son males que puedan eliminarse desde los centros con prácticas de exorcismo, sino con la decisión de Ilegar a un Nuevo Orden Económico Internacional para cooperar en la transformación interna de los paises en desarrollo que se propongan hacerlo. Tiene que haber en esto acciones convergentes cuya mecesidad dista mucho de reconocerse, así en los centros como en la periferia.

Es notoria la renuencia de los centros. No podría negarse, sin embargo, que abrumados por sus serios trastornos, se ven llevados a postergar ciertas decisiones importantes que reclaman los paises en desarrollo. P'ero thay en esta actitud mucho más que dificultades circunstanciales. La prueba de ello está en lo que ha sucedido en los langos años de bienandanza que preceden a la crisis que tanto preocupa ahora. Los centros, salvo algunos de ellos, que no están entre los mayores, han sido indiferentes a las demandas periféricas, para decir lo menos.

No tha habido, por lo demás, correspondencia entre esas demandas y lo que los paises en desarrollo tendrían que hacer en un gran esfuerzo de transformación. Suele aflorar. esta falta de correspon- 
dencia en las discusiones que los economistas periféricos tenemos con los de los centros. Se nos reprocha nuestra insistencia en una mayor cooperación financiera cuando podriamos emplear más y mejor nuestros propios recursos de inversión. Y se nos dice además que mientras folicitamos a los centros eliminar las trabas $y$ restricciones ique se oponen a nuestras exportaciones, no hemos sido capaces de dar gran impulso al comercio recíproco entre países periféricos.

Hay que reconocer sin reticencias la validez de estos argumentos. Pero a la luz de mi experiencia me inclino a creer que se trata más bien de argumentos polémicos que de una incitación a trabajar mancomunadamente -centros $y$ periferias- para llegar a una vercladera estrategia global de desarrollo.

\section{LA TEORIA DE LOS GENTROS}

Las afirmaciones que acabo de formular me obligan a exponer claramente mi pensamiento acerca del capitalismo periférico y su articulación de los centros. Declaro ante todo que al interpretar estos fenómenos me he emancipado por completo de las teorías económicas convencionales, especialmente las teorías neocláricas, que than rebrotado con vigor en la América Latina y en algunos paises tienen gran influencia en la política económica.

En mi lejana juventud fui un economista neoclásico. seducido por el rigor lógico de estas teorías y por su elegancia matemática. Demostraban terminantemente que el sistema económico, librado a sus propias fuerzas, en plena competencia y sin intervención alguna del Estado, tendía persistentemente thacia posiciones de equilibrio en que los factores productivos se asignaban en forma óptima $y^{\prime}$ se remuneraban según su aportación al proceso.

Desgraciadamente no es así; pues de serlo, se habrian simplificado de un modo inconcebible los problemas del desarrollo cada vez más complejos. Después de larga experiencia y un perseverante esfuerzo de interpretación tcórica, muchas veces interrumpiclo por las exigencias de la praxis, tuve que ir desbaratando mucho de lo que ha. bía aprendido y' enseñaclo; y' sólo con el andar de los años me siento en condiciones te ofrecer a la controversia un esbozo de mi propia interpretación del desarrollo periférico.

He procurado llegar a una interpretación global que abarque los clementos más importantes del desarrollo. Son elementos económicos, tecnológicos, sociales, culturales y politicos. Proponerse explicar la realidad a la luz de una teoría solamente económica es perderse irremisiblemente en un callejón sin salida.

Mi intempretación no es sólo global en este sentido, sino que atañe 
asimismo a ciertos fenómenos del clesarrollo de los centros capitalistas que influyen considerablemente en el capitalismo periférico.

Aquellas teorias elaboradas en los centros tienen un falso sentido de universalidad, acaso porque supusieron que el capitalismo periférico reproduciria simplemente el capitalismo de los centros. Suposición implicita tanto en los neoclásicos como en el pensamiento marxiano y, desde luego, en Keynes, en cuyas teorias no aparece para nada la periferia.

Pero no se intenprete este aserto como que estoy buscando una teoría independiente; sería una aberración. Se trata de dar a la teoría un verdadero sentido de universalidad integrando en ella la especificidad de los fenómenos del desarrollo periférico.

Esta especificidad tiene su origen en el retardo histórico del desarrollo integral de nuestros países, si por tal se entiende un proceso que va mucho más allá del papel de suministrar productos primarios a los centros. El desarrollo integral se inicia tardiamente con la industrialización y otras formas cle penetración de la técnica de los centros.

Surge inmediatamente una pregunta al considerar este hecho. ¿Por qué a pesar de este retardo histórico no se reproduciría el capitalismo de los centros? En la respuesta encontraremos la clave de nuestra interpretación. Tratemos ahora de ofrecerla:

Hemos mencionado anteriormente el carácter imitativo de nuestro capitalismo. Se desenvuelve el proceso en la órbita hegemónica de los centros -sobre todo el centro dinámico principal del capitalismo-, $y$ de ellos se propagan la técnica, las modalidades de consumo y otras formas culturales, las instituciones, las ideas e ideologías. Pero eștos fénómenos de propagación e imitación se realizan en unar estructura social muy diferente de la estructura de los centros debido precisamente a ese retardo histórico. Surgen así grandes contradicciones a las que se agregan las de las relaciones con los centros. Unas $y$ otras imprimen al desarrollo periférico un sentido excluyente $y$ conflictivo que tienden a llevar al sistema a grandes trastornos económicos y' sociales con muy serias consecuencias políticas.

\section{LLOS FENÓMENOS DE PROP,AGACION DE LOS CENTROS EN LA ESTRUCTURA SOCIAL DE LA PERIFERIA}

Veamos primero las contradicciones internas de la periferia. Ha de comprenderse que dada la brevedad y el carácter de mi trabajo tendré que ser muy esquemático, valiéndome de trabajos ya publicados $y$ en publicación.

La penetración de la técnica de los centros tiene un papel importantísimo en el desarrollo, puesto que su creciente productividad 
permitiría elevar persistentemente el nivel de vida de la población. Pero este mejoramiento tiene un ámbito muy limitado, el ámbito de la sociedad de consumo que abarca primero a las estratos superiores de ingrgeso y se wa extendiendo a los tramos más altos de los estratos intermedios. Queda en el fondo de la estructura social la sociedacl de infraconsumo, en donde vegeta una masa considerable cle la población a la cual no llegan, o apenas llegan, los frutos del desarrollo. Se estima conjeturalmente que esa masa de estratos inferiores de ingreso constituye no menos del $110 \%$ de la población aunque con grandes variaciones de país a país. Tal es la flagrante desigualdad del capitalismo periférico.

Hay quienes sostienen que ello ha sido creado por el mismo capitalismo. Hay aquí una confusión que conviene disipar. No es así a mi juicio. Esos estratos inferiores constituían una proporción mucho más alta antes de la industrialización. Y al desenvolwerse este proceso ha renido disminuyenclo, gracias a la capacidad absonbente de fuerza de trabajo del desarrollo capitalista. Pero esta capacidad tiende a debilitarse y el sistema se ha vuelto excluyente, aun cuando en aquel ámbito limitado del desarrollo se alcancen muy elevados indices de prosperidad, si no de opulencia. Y aquí se encuentra uno de los fenómenos que tienden hacia la crisis del sistema.

¿Cómo se explica esta tendencia excluyente? ¿ए队or qué los frutos de la mayor productividad que la penetración de la técnica trae consigo se circunscriben a aquel ámbito limitado de la sociedad de consumo?

La explicación radica en la estructura social que permite la apro. piación primaria cle esos frutos de la propagación de la técnica por los estratos superiores de ingresos que concentran en sus manos la mayor parte de los medios productivos.

Desde el punto de vista cle la técnica, la estructura social está dada por una gran diversidad de capas técnicas segrún su productividad, desde las más avanzadas según las condiciones periféricas, a las capas inferiores, en algunos casos semicapitalistas o precapitalistas.

El proceso dinámico del desarrollo se caracteriza por una continua superposición de nuevas capas técnicas de creciente productividad a las capas técnicas precedentes de inferior productividad. $Y$ la fuerza de trabajo empleada en ésta tiende a absorberse por aquellas otras ${ }^{2}$.

Ahora bien, al absorberse en esa forma la fuerza de trabajo que radica en las capas inferiores, las remuneraciones no suben correlativamente con la mayor productividad de las nuevas capas técnicas

La fuerza de trabajo abarca toda la población activa, ocupada o no, desde la que carece de calificaciones a las que tiene las calificaciones más elevadas. 
y el atimento de productividad de las capas precedentes. Aquí encontramos un fenómeno estructural de considerable importancia, más bien clioho cle s:gnificación decisiva en el funcionamiento del sistema.

¿Cómo se explica este lenómeno? ¿Por qué ia fuerza de trabajo atsorbicla con creciente productividad en las capas técnicas superiores no logra mejorar proporcionalmente sus remuneraciones en el juego de las fuemas del mercado?

La explicación radica fundamentalmente en la estructura social. Hay, en efecto, en la periferia, una masa considerable de gente ocupada con muy baja productividad $y$ exiguos ingresos en las capas técnicas inferiores, si bien con notables diferencias entre países. Pues bien, a medida que se absorbe esa gente en las capas técnicas superiores no suben correspondientemente las remuneraciones porque la competencia del gran número que se encuentra en tales capas, gravita pesadamente en contra.

Hay aquí una desproporción muy seria entre la demanda y la oferta de fuerza de trabajo que tendría que ser absorbida. Esta clesproporción es un fenómeno típico del clesarrollo periférico. Tenciría que elevarse fuertemente el ritmo de absorción para que, al clisminuir progresivamente la fuerza de trabajo de las capas técnicas inferiores, se debilitara esa competencia socialmente regresiva. Pero la acumulación de capital es absolutamente insuficiente, no sólo frente a las grancles dimensiones del problemá cle absorción de fuerza de trabajo, sino también frente al extraorclinario crecimiento de esta última. Y aunque fuera suficiente ayudaria a resolver, pero no bastaría para resolver con equidad el problema de la distribución. Comprobamos aquí otro de los fenómenos de propagación de los centros, a saber de los avances cientificos y técnicos que defienden $y$ prolongan la vida humana, y su clesigual incidencia en la estructura social.

De todos modos, el proceso de absorción de suyo es dilatado, pero la estructura social y los fenómenos de propagación de los centros, no solamente lo hacen más dilatados aún, sino que dan lugar a la tendencia excluyente que se dijo más arriba. Es muy simple la explicación de una realidad por cierto compleja. Veámoslo.

La propagación de la técnica de los centros trae un aumento continuo de productividad, que permitiría clevar el ritmo de acumulación de capital $y$ la capaciclad absorbente del sistema. Pero ello no ocurre porque ese potencial de acumulación se clesperdicia en gran parte por la imitación de las formas de consumo de los centros.

Esta imitación no podría darse con la intensidad con que ocurre sin una gran des'gualdad en la distribución del ingreso. Y esta de- 
sigualdad tiene su origen primordial en otro fenómeno esencialmente estructural, a saber la aptitud que tienen los estratos superiores que concentran en sus manos la mayjor parte de los medios productivos para apropiarse primariamente de la mayor productividad que la propagación de la técnica trae consigo.

Para comprenderlo, recuérclase lo que se dijo más arriba acerca de lat clebiliclad de gran parte de la fuerza de trabajo para elevar sus remuneraciones correlativamente al aumento de procluctividad. Sólo están en condiciones de hacerlo quienes, en buena parte por su poder social, pueden adquirir las calificaciones exigidas de mís en más por la propagación cle la técnica. Ello representa una proporción mucho menor, desde luego, ique la que constituye aquella gran masa de [uerza de trabajo ocupada en capas técnicas inferiores o en servicios personales de muy baja o ningtina calificación.

Así, pues, una parte consiclerable de este aumento de productividacl por la propagación de la técnica queda en manos de los propietarios de los medios productivos, además de la remuneración que les corresponcle por sus tareas empresariales. Tal es el fenómeno del excedente que constituye la piedra angular de nuestra critica al capital:smo periférico. In el excedente se cncuentra el punto cle particla cle la ciesigualdad en lit estructura social. Es la parte de los aumentos de productividad que, habida cuenta de la remuneración empresarial, no tiencle a trasmicirse a la fuerza de trabajo, salvo en aquella parte de esta última que tiene las calificaciones crecientes exigiclas por la penetiación cle la técnica, como se ha mencionado anteriornente. $Y^{\prime}$ lo que así no tiencle a trasmitirse, explica el papel creciente del poder sind"cal $y$ político que se desenvuelve independientemente cle las fuerzas del mercaclo. No tiene en realidad la mayor parte de la fuerzal de trabajo en el capitalismo periférico otra manera de compartir el fruto del progreso técnico. De ahí que la distribución tienda a cleterminarse cada sez más por el juego de las relaciones de poder.

Los economigtas neoclásicos no admiten este fenómeno estructural del excedente. No es extrañit esta actitud pues ignoran en gran parte la estructura social en sus razonamientos. Para ellos la gamancia empresarial resultante del atumento de productividad es un thecho transitorio que tiende a desaparecer en un régimen de competencia, seat por el aumento de remuneraciones, sea por el descenso de los precios. Sólo queda en manos de los empresarios la remuneración de su prop:o esfuerzo productivo.

Acabo de sostener que las remuneraciones no se elevan correlativamente al aumento de productividad $y$ sostengo también que no se traslada a la colectividad por el clescenso de los precios aun en un réginen da ibschluta libre concurrencia, que no existe por cierto. 
He tratado de demostrarlo en mis trabajos y no me parece oportuno entrar aquí en ello, por importante que fuere?.

Antes de proseguir conviene hacer una digresión importante. Decíamos más arriba que la fucrza de trabajo que tiene las calificaciones crecientes exigidas por la penetración de la técnica tiene aptitud de compartir el fruto que de ella se deriva. En este compartimiento se manifiesta su aportación al aumento de productividad en función de su capacidad $y$ ' dinamismo individuales. La teoría neoclásica trata de dilucidar con precisión este punto. Sin embargo, la estructura social tiene también considerable importancia, pues la formación de capacidades es en gran parte el resultado del poder social, esto es, la posibilidad efectiva que tienen los individuos, según su posición estructural para aprovechar las oportunidades de tormación. Aptitud que desciencle cuando se baja en la estructura hasta rolverse insignificante o inexistente en los estratos inferiores.

Ahora bien, a medida que clisminuye en esta forma el poder social, va surgiendo eni el curso del desarrollo, por las mutaciones estructurales qque la penetración de la técnica trae consigo, el poder sindical y político de la fuerza de trabajo en los estratos incermedios de ingreso, conforme se abre paso al proceso de democratización. El poder sinclical y político consigue as ́compartir el excedente. Pero, por otro lado, el excedente va creciendo con nuevos aumentos de productividad.

Antes de entrar en este proceso redistributivo, de donde surgen con el andar del tiempo los fenómenos conflictivos del capitalismo periférico, conviene explicar aquella tendencia excluyente del sistema que decíamos en otro lugar. Uno y otro fenómeno se explican fundamentalmente por la forma de apropiación del fruto de la penetración estructural de la técnica.

Volvamos ahora el excedente. El excedente representa, ya se dijo, un gran potencial de acumulación. de capital. De la eficaz utilización de este potencial depende en gran parte el ritmo de absorción

Básteme plantear aquí esta pregunta ¿Por qué los precios no bajan correlatitamente con el aumento de prosluctividad esparciendo entre todos los frutos de la propagación cle la técrica? Plies sencillamente porque en la dinámica del desarrollo, para acrecentar la producción, las empresas tienen. que pagar a los factores productivos de los bienes que se van elaborando ingresos superiores a los contenidos - por decirlo asi- en los bienes terminados que afloran en cl mercado. Se trata del tiempo que tarda la producción. Pues bien, estos mayores ingresos, cubiertos con expansión monetaria, crean un incremento de demanda que absorbe los bienes adicionales provenientes del aumento de productividad que trae consigo. Todo ello aun cuando rige la más absoluta competencia entre las empresas. Tal es mi cxplicación muy esquemática de un asunto más bien complejo. Dicho sea de paso que generalmente se olvida que la exprnsión monetaria es inherente al acrecentaniento de la producción. 
de la fuerza de trabajo de los estratos inferiores. [P'ero esto es incompatible con cl establecimiento de la sociedad de consumo a imagen y semejanza de los centros.

Más aun, la ekrolución tecnológica de los centros presenta dos manifestaciones que, si por lo general van estrechamente unidas, tienen gran significación en la sociedad de consumo de la periferia. Una manifestación corresponde al incremento de productividad gracias a la acumulación cle capital. La otra está relacionada a la diversificación incesante de los bienes $y$ servicios, tambión gracias al acrecentamiento de capital.

Ahora bien, el capital de donde surge el aumento de productividad es de carácter reproductivo, pues tal aumento da lugar a una nueva acumulación con incremento adicional de productiviclad y así sucesivamente. $Y$ si bien al acrecentarse la productividad disminuye la capacidad absonbente de capital, no lo es menos que en ese proceso de acumulación sucesiva se va muitiplicando el empleo.

En cambio, la clikersificación exige generalmente un capital que no es reproductivo en el sentido anterior, pues no trae consigo aumentos sucesivos de procluctividad y empleo. Se trata de un capital consuntivo. También se da este caso en la vivienda, principalmente en los estratos superiores, y los trabajos públicos más allá de cierto nivel, por la exageración de capital consuntivo: crean empleo momentáneamente pero no lo multiplican.

En los centros la diversificación de bienes y servicios se va desenvolviendo a medicla que aumenta la productividad y se cumple el papel absorbente del capital reproductivo. En la periferia, sin embargo, la imitación de formas avanzadas de diversificación se realiza prematuramente en desmedro del capital reproductivo y su papel absorbente.

Tales son las consecuencias de la sociedad de consumo. Cuanto más impulso adquiere, tanto más se manifiesta su tendencia exclum yente de los estratos inferiores de ingresos.

He ahí una de las grandes contradicciones del desarrollo imitativo. La propagación de la técnica de los centros, por su productividad creciente, entraña un potencial de acumulación de capital cada vez mayor. Pero ese potencial se desperdicia principalmente en la imitación del consumo $y^{r}$ de las modalidades de consumo, según acaba de verse. Hay también otras formas de desperdicio que se mencionan a su tiempo.

Mientras así se debilita relativamente la acumulación de capital, crece en forma extraordinaria la fuerza de trabajo por la propagación de los adelantos científicos y tecnológicos que defienden y prolongan la vida humana. Otra contradicción de extraordinaria importancia. 


\section{LAS TENDENCIAS CONTLICTIVAS DEL SISTEMA}

Este fenómeno tan importante de desperdicio del potencial acumulativo también trae consigo tendencias conflictiras de la distribución del ingreso dentro del ámibito limitado del desarrollo en que prevalece la sociedad de consumo.

Esta tendencia conflictiva, que tiende con el anclar del tiempo a trastornar el sistema, refleja también un fenómeno estructural. 'Para comprenderlo recuérdese lo que dijimos acerca de la apropiación primara por quienes concentran asimismo el poder social, y lo que se dijo también acerca del poder sindical y politico que, conforme avanza la democratización, se desenvuelve en los estratos intermedios $y^{\prime}$ les hace compartir en mayor o menor grado el fruto de la mayor productiviclacl.

Estos estratos intermedios se van formando $y$ ampliando a medida que la técnica penetra mediante la industrialización y el clesenvolvimiento de otras actividacles, así en el campo de las empresas como en el Estado $y$ los servicios personales. Este fenómeno va acompañado de la concentración urbana - por razones técnicas y estructurales-$y$ de la formación de conciencia social en tales estratos, tanto por la educación como por las técnicas cle comunicación y difusión social. Todo ello ofrece las condiciones propicias para el avance de la democratización en el cual la propagación de instituciones e ideologías de los centros es de primordial importancia.

En esto como en otros aspectos, es muy estrecha la correspondencia con la estructura social $y$ sus mutaciones. Entre una fase inicial de clemocratización incipiente $y$ una fase avanzada de gran impulso democrático hay una gama de situaciones con clistintos grados de contención y manipulación del avance de este proceso de democratización formal y clemocratización substantiva.

Desde luego, la intensidad del poder sindical y politico y sus consecuencias redistributivas está ligada estreohamente a estos fenómenos de democratización. Bastan unas breves líneas para comprenderlo.

El poder sindical se manifiesta en la pugna para defender o au. mentar el nivel de remuneraciones. En tanto que el poder político se empeña en conseguir ventajas sociales (șalucl, educación, vivienda, seguridad social). Estas ventajas se costean generalmente con contribuciones que, en una u otra forma, tienden a trasladarse sobre los precios más allá de cierto límite y acentúan de este modo la pugna por el aumento de remuneraciones.

Ocurren también aumentos de precios de origen externo e interno, que si bien se originan fuera de la órbita redistributiva, acentúan asimismo la pugna, en clefensa de las remuneraciones reales. 
Finalmente, hay que mencionar dos puntos importantes que atañen a la acción del Estado. Uno de ellos suele adquirir creciente importancia. Concierne también. al poder social. Pero ya no se trata del poder que permite responder a las crecientes exigencias de calificaciones que la penetración de la técnica trae consigo, sino más bien a la formación de aptitucles consuetudinarias o convencionales que Llevan con frecuencia connotaciones de prestigio o jerarquía social. La presión del poder social apoyada en el poder politico lleva a un fenómeno de aibsorción espuria de la fuerza de trabajo en la administración del Estado y las empresas públicas. A veces, en la empresa privada ocurre un hecho similar bajo presión sindical. Trátase de otra forma de desperdicio del potencial de acumulación, ya sea que se financie con impuestos o con la expansion inflacionarıa clel crérlito cuyas consecuencias recaen finalmente sobre el excedente.

E1 otro punto que atañe a la acción del Estado también se manifiesta en la expansión crediticia. Pero en este caso se clebe a factores exteriores, pues el clescenso cíclico en que éstos se manifiestan, lleva generalmente a esa expansión para atenuar el efecto interno de la contracción exterior.

Todos estos elementos se combinan en la realidad de distintas maneras $y$ en diferentes grados. 'Y conforme se desenvuelve el poder sindical $\mathrm{y}$ político de los estratos intermedios con el avance de la democratización, según antes decíamos, se va acentuando la pugna distributiva en su empeño de compartir el excedente con los estratos superiores. Mucho más duando la democratización va extendiéndose a los estratos inferiores de la estructura social.

\section{HACIA LA CRISIS DEL SISTDMAA}

Lo grave de todo esto se encuentra en que tanto la retención y crecimiento del excedente por los estratos superiores como sur compartimiento por los estratos de más abajo en virtud de su poder sindical y político no obedecen a principio regulador alguno ni están guiados por consicleraciones de equidacl social.

Cuando el poder sindioal y político está contenido o limitado en una u otra forma, la pugna distributiva no afecta la estabilidad de precios, $\mathrm{y}$ pueden aplicarse las reglas del juego monetario. El poder de los estratos superiores apoyado por la autoridad monetaria no permite que los precios internos excedan a los intennacionales. Más allá de ciertos límites, el exceclente se vuelve inexpugnable.

Esto ha pasado a ser una figura del pasado en los paises en que va adquiriendo intens:dad el poder sindical y politico $y$ en tque cl poder social presiona insistentemente sobre el Estado. Así, pues, la pugna 
redistributiva lleva fatalmente a la espiral inflacionaria. La inflación pasa a ser un fenómeno inherente a las fases estructurales avanzadas del clesarrollo.

Ocurre entonces un verdadero destronamiento de la autoridad monetaria y el Estado se vuelve impotente ante el juego cle relaciones de poder que determinan cada vez más la distribución del ingreso.

Todo ello gira incesantemente on torno al excedente. El excedente está sujeto a dos movimientos contrarios. Por un lado se acrecientan nuevos aumentos cle productividad. Por otro, disminuye en la medida en que lo comparten el poder sinclical $y$ político.

Ahora bien, en la dinámica del capitalismo periférico es esencial acrecentar continuamente la acumulación de capital reproductivo, por más que éste sea focialmente insuficiente. Si se resiente el crecimiento del excedente, disminuy'e el ritmo de acumulación y', al suceder esto, clisminuye la formación de nuevos excedentes, y así sucesivamente. Todo ello influye de un modo adverso sobre el ritmo de desarrollo y de absorción de fuerza de trabajo, con lo cual se acentúan las tenclencias excluyentes y conflictivas del sistema. Lo malo de cste proceso acumulativo está en que el excedente también da lugar a la inequidad distributiva.

Las mutaciones estructurales no sólo quitan toda eficacia a la restricción crecliticia para impedir el alza de precios sino que la vuelven contraproducente. 'P'ues el pocler sindical y' político, en el avance irrestricto de la democratitación sigue presionando el alza de remuneraciones, y si la autoridad monetaria restringe el crédito para evitar el traslado sobre los precios, sólo consigue provocar la contracción de la economía, sin frenar la inflación, con lo cual el excedente disminuye o clesaparece, con las consecuencias ya señalad ıs. $Y$ las consecuencias de la contracción lo obligan tarde o temprano a expandir el crédito. Sufre un verdadero destronamiento la autoridad monetaria. Lo mismo cuando se opone a la devaluación exigida inevitablemente por la inflación interna.

Pero no es eso solamente. Cuando Ia autoridad monetaria se we forzada a cecler a la presión inflacionaria y devaluar la moneda, adquiere nuevo impulso la espiral inflacionaria y cada ruelta se proyecta con mayor amplitud. Fenómeno bien conocido que, aclemás cle afectar al excedente, tiende a llevar al desbarajuste económico y la clesintegración, social.

Existe en verdad un cierto determinismo en este proceso que no se daba anteriormente, $y$ es trágica la situación de aquellos thombres que, con gran sentido de responsabilidad, tratan de frenar a este fenómeno. Pues sólo disponen de paliativas o son arrastrados a medicias de inflación reprimida que trastornan más el sistema y provocan finalmente un más fucrte impulso a la inflación. 
iPodria, sin embargo, mencionarse el caso de países que parecerían litwarse de ese proceso. Unos porque se encuentran en una fase de desarrollo incipiante, otros porque gozan de la explotación de un recurso natural que los provee de fondos abundantes. La pugna distributiva no acontece entonces entre estratos intermedios para compartir el excedente con los estratos superiores, sino para distribuir esos fondos extraordinarios sin desmedro del excedente, antes bien, acrecentándolo. El avance democrático se ruelve asi compatible con la exaltación de la sociedad de consumo, la cual se abre de más en más a los estratos intermedios. Pero apenas llegan las migajas a los astratos inferiores. Cabe preguntarse si esta euforia cle privileg.os puede mantenerse indefinidamente.

Sea cle ello lo que fuere, el atvance de la democratización parecería volverse incompatible con el desenvolmiento regular de la sociedad de consumo en el ámbito limitado del desarrollo. E1 poder sindical y político de los estratos intermedios $-y$ más si los inferiores despiertan de su pasividad- se supenpone entonces al poder de los estratos superiores y pasa a dominar la escena política social. Pero en el exceclente radica el centro dinámico del sistema $y$ las consecuencias de su debilitamiento y desaparición, agravadas frecuentemente por la evasión cle capitales, aumentan aquellos trastornos y, a falta de consenso político, se impone el empleo de la fuerza.

El empleo de la fuerza permite frenar o suprimir el poder sindical y político de las masas y restablecer el excedente $y$ su potencial de acumulación, hacienclo retroceder lo que se habría ganado más allá de ciertos límites en la presión redistributiva. Dicho sea en verdad que no hay sistema dinámico que pueda prescindir del excedente. Pero en el capitalismo periférico, el excedente, como ya hemos visto, es lo que permite la imitación del consumo de los centros, y el costo del restablecimiento de la clinámica cle sistema es un nuevo impulso de la sociedad de consumo en claro desmedro de la absorción de los estratos inferiores. ICosto social y también costo político: ambos de ingentes dimensiones.

\section{LAS CONTRADICCIONES EN LAS RELACIONES CENTRO-PERIFERIA}

Después de este examen, sobremanera esquemático de los fenómenos del desarrollo interno de la periferia latinoamericana abordaremos las relaciones con los centros industriales.

También aquí hay que disipar un mito persistente. El de la expansión espontánea del capitalismo cle los centros en la periferia. No hay, ni da halbido tal tendencia. Llevados por su propia dinámica, las centros than desenvuelto su industrialización dentro de ellos mismos $y$ asi tambión su intercambio de bienes industriales. Sólo 
les ha interesado espontáneamente la periferia en cuanto es produc tora de bienes primarios que necesitaban. La industrialización de la periferia ha sido un proceso deliberado resultante primero de crisis sucesiras de los centros $y$, después, vencidas resistencias internas y externas, de una politica no siempre accrtacla. ILos centros se than inconporado después mediante las transnacionales, atraidos por la protección o el subsidio.

Las transnacionales constituyen nuevas formas de articulación de los centros al desarrollo periférico. Pero no ha venido acompañada esta articulación de la eliminación de las contradicciones provenientes del retardo histórico del desarrollo periférico en las relaciones centro-periferia. Antes bien, se han agravaclo.

Los centros han sido siempre fuentes de capital y tecnología parat lat periferia y nadie podrá negarlo. Pero sucede que la periferia acude en gran parte a las transnacionales para suplir con sus inversiones y otras aportaciones de recursos internacionales que generan, a fin die llenar el vacío que la sociedad de consumo deja en la acumulación nativa de capital. Por lo demás, la contribución de las transnacionales resulta a la larga en buena parte ilusoria en cuanto al proceso acumulativo.

Las transnacionales se vinculan así a la sociedad de consumo; $y^{\prime}$ si bien ésta se suștenta soibre la desigual distribución del ingreso, no lo es menos que contribuyon poderosamente a exaltarla mediante la eficaz utilización de los medios de comunicación y difusión social.

Si bien se reflexiona, si los estratos privilegiados (superiores y partc alta de los intermedios) emplearan a fondo su potencial de acumulación, no se habria desenvuelto con intensidad la sociedad de consumo ni las transnacionales hubieran encontrado un campo tan fértil para sus operaciones. $\mathrm{El}$ acento se thubiera puesto entonces en la aportación de técnicas que acrecientan la productividad antes que aquellas otras técnicas de diversificación de bienes atvanzados que insumen capital consuntivo en clesmedro del capital reproductivo, como antes se tiene dicho.

Procura la periferia atraer las transnacionales para acelerar el ritmo de desạrollo y lo consigue en algunos casos. Tal es la aceleración diel desarrolio por manos ajenas, antes que por manos propias, pero sin que ello corrija aquellas contradicciones de donde dimanan los fenómenos excluyentes y conflictivos del capitalismo periférico.

No sólo eso, sino que surge una nueva y seria contradicción. Los centros alientan en diversas formas la expansión periférica de las transnacionales y suelen brindar recursos financieros como inceñtivo, sea directamente, sea mediante instituciones de crédito internacional. Pero como es bien sabido, no facilitan la entrada de productos peri- 
Lúricos para pagar los servicios financieros que devengan las transnacionales, cicrtamente cuantiosos, y las crecientes importaciones que exige el desarrollo. IDc estas importaciones asi como de esos servicios financieros surge la tendencia al clesequilibr'o exterior de la periferia, agravado por la inflación.

tha periferia ha quedaclo excluida en gran parte de la liberalización del intercambio industrial. En el GaTr se han rebajaclo derchos para los bienes técnicamente avanzados que constituyen principalmente al comercio recíproco de los centros $y^{\prime}$ en los cuales la perileria no podría competir espontaneamente, pero no se ha liberalizado la importación de aquellos bícnes menos avanzados, o que han dejado de serlo, en los cunles poclria competir la periferia. Las preferencias que tras larga lucha ha logrado la periferia para estos bienes son. verdaderamente desconcertantes. ICompréndese así el acento que los países en desarrollo han puesto acerca de la liberalización efectiva de eqtos bienes en la formulación del Nucvo Orden Económico Internacional.

Es cierto que las transmacionales, estimuladas por subsidios $y$ otras facilidades, han abanclonado en parte su renuencia a exportar, especialmente aquellos b:enes avanzados que en el intercambio. de los centros han pasado it un orden sccunclario. Pero muy poco exportan a los centros, al menos por ahora. Lo hacen gencralmente dentro de la misma periferia, lo cual, si es positivo, no deja de ser una nueva manifestación de aquel fenómono de acelerar el desarrollo por manos ajenas, en vez de clar impulso a las propias manos clando vigor $y$ persistencia a los alreglos de intercamibio recíproco.

Si bien se reflexiona, las transnacionales tienen un papel muy importante en la internacionalización del consumo, en aquella propagación prematura cle formas avanzaclas de consumo de los centros gracias a las clesigualdades distributivas. Pero por lo que acaba de clecirse clistan mucho de internacionalizar la producción, salvo en curnto convione a sus intereses comerciales.

Es obvio, pues, que la articulación de las transnacionales al tipo prevaleciente de desarrollo periférico adolece de serias manifestaciones de irracionalidad, descle el punto de vista cle ese mismo desanollo, pues no significa una contribución ponderable a la solución del grave problema de estrangulamiento exterior. Los gobiernos de los centros Ias alientan y amparan, pero no siguen una politica racional de cooperación con la sociedacl de consumo. No es que yo defiencla a esta última, pues la considero una aberración desarrollista. Simplemente quicro senalar una de las tantas inconsistencias de los centros en sus relaciones con la periferia.

Otra manifestación de inconsistencia está en la pertinaz oposición hacia medidas que atenúen el efecto mur perturloador de las fluc- 
tuaciones exteriores. El centro clinámico principal ha encabezaclo la resistencia a los acuerdos de estabilización de productos básicos, aunque thay síntomas allora de que esa resistencia está allojando. Se invocan las sacrostntas leyes del mercado, pero cuando conviene a sus intereses no vacilan en olvidar esas leyes. Pero no las violan. Los grancles no suelen hacer eso. Cuando ciertos principios no les acomodan inventan otros. Así los Estados Uniclos vuelven a restringir deliberadamente sus cultivos de granos para evitar la caída de sus precios en el mercaclo internacional. Y la Comuniclad Económica Europea no es ajena: al este género de manipulaciones.

Hay que reconocer, sin embargo, que la Comunidad ha iniciado ciertas medidas positivas para atenuar la vulnerabilidad exterior de los países africanos asociados, mediante compensaciones financieras. Es un conienzo modesto pero significativo, cuya experiencia podria aprovecharse en la formulación cle una más amplia política de compensación internacional.

WHay quienes consicleran en los centros que éstas y otras mediclas de cooperación fianciera, según ya dije en otro lugar, van a farrorecer en última instancia a los estratos privilegiados de la perileria. Es cicrto, pero la vulnerabiliclat exterior tamíbién recae sobre la ocupación y los ingresos de la mayoría de la población.

$\mathrm{Si}$ estas objeciones dicran impulso a una vigorosa política de cooperación con aquelios países periféricos que se proponen transformar fundamentalmente su sistema para conseguir equidad e impulsar la clemocratización, yo me encontraría entre los primeros que habrian de aplaudir semejante actitud.

Fero desgraciadamente los centros no están preparados para ello y cuando en la periferia se ha quericlo introducir cambios conducentes a la transformación del sistema, se ha movido frecuentemente en contra toda la constelación cle intereses soliclarios que en los centros giran en tomo a las transnacionales.

Punto éste de gran significación y que atañe a la médula del tema sobre el cual se me ha sugericlo clisertar. Justifícase, pues, explayarse sobre ello.

La hegemonía histórica de los centros, con nuevas modalidades que suelen fortalecerlat, se encuentra siempre en el trasfondo de las. relaciones centro-periferia. Bajo el signo de exa hemonia, de la superioriclad económica y tecnológica de aquéllos y el retardo histórico del desarrollo periférico, se cumple la expansión cle las transnacionales y surgen nuevas formas de succión de ingresos que se añaden a otras inveteradas y debilitan la acumulación de capịtal. Resortes primordiales del desarrollo son manejados descle afuera.

Todas estas manilestaciones de hegemonia hatn sido compatibles 
con aquellas fases iel desarrollo periférico en que la democratización era incipiente o estaba contenida o manipulada, según antes sa tha expresitlo. P'ero conforme el proceso de democratización va abriéndose paso gracias a las mutaciones estructurales surgen tamtuién fenómenos de resistencia a tales manifestaciones hegemónicas que se agregan a los cambios internos de las relaciones de poder $y$ sus consecuencias sobre la distribución del ingreso.

Las transnacionales gravitan intensamente en estas relaciones de poder no sólo en la pugna distributiva sino también porque comparten en cierto modo la gravitación politica de los estratos superiores, además de la muy fuerte que tionen en los centros.

Hay en ello elementos culturales que no siempre se comprenden bien descle afuera. $\mathbb{E}$ l desarrollo - ya lo expresamos- no es simplemente un proceso económico. Las mutaciones estructurales, la formación y ampliación cle los estratos intermedios, traen nuevas aspiraciones, desenvuelven un sentido de identidad nacional, de autonomía de decisiones, de conciencia cada vez mayor de sus propios intereses, que termina por reaccionar contra esas manifestaciones de hegemonía.

Por mucho que estas reacciones estén frecuentemente cargadis te emotividad, rellejan problemas de fondo que los poderosos se obstinan generalmente en ignolar. No es, pues, extraño que los fenómenos conflictivos del desarrollo interno vayan también acompañados de fenómenos similares en las relaciones centro-periferia, fenómenos, unos y otros, que suelen agravarse por los efeqtos adversos de la vulnerabilidad exterior.

Suele entonces moverse en contra del país periférico esa impresionante constelación de intereses que, según cleciamos, gira en torno a las transnacionales $y$ sobrevienen diversas medidas punitivas y no es raro, como bien sabemos, el empleo de la fuerza.

\section{LA CRISIS DEL SISTEMTA}

No hay necesariamente una sincronía entre ambos fenómenos conflictivos y su clesenlace. Pero el empleo interno de la fuerza a que llevan los graves trastornos del sistema, contribuye a atenuar, si no evitar, fenómenos conflictivos externos o a facilitar su solución.

Como quiera que fuere, el pleno restablecimiento de la sociedad de consumo ofrece campo propicio a las transnacionales, cuyas inversiones $y$, extraorclinaria productividad contribuyen a la euforia de aquélla. Más aun, el freno o supresión del poder sindical y politico permite presionar thacia abajo el nivel de las remumeraciones reales en favor del excedente, con lo cual la inversión nativa puede subir, 
no tanto por el esfuerzo de quiones disfrutan más que nunca de la sociedad de consumo, sino de grandes masas de la población.

En la medida en que se acreciente en este proceso la inversión reproductiva, puede también darse mayor intensidad a la absorción de los estratos inferiores en parte con formas regresivas de absorción, pero sin corregir la desigualdad con los de más arriba, y especialmente con los que se encuentran en Ia cúspide del sistema. Por lo contrario, Ia desigualdad se agranda y se vuelve más impresionante el contraste de la sociedad de consumo con las masas que regetan en la de infraconsumo.

No es extraño que en tales condiciones rebroten, a veces con extraordinario vigor, las teorías neoclísicas. Triunfo tardío pero muy significativo del largo y pertinaz esfuerzo de la Escuela de Chicago para domeñar a la CEPAL y destruir sus herejías en materia de desarrollo e industrialización, de equidad clistributiva y comercio internacional. Herejías que on varios casos han dejado de serlo, aun para algunos adeptos a aquellas enseñanzas, sobre todo cuando tienen que enfrentar la realidad periférića.

En un plano de objetividad tiene que reconocerse que ese reflorecimiento neoclásico se explica as.mismo por las variadas formas de intervención contraproducente del Listado en la economía. Meclidas de clara inspiración populista, en algunos casos y, en otros, provocadas por la muy comprensible reacción de hombres responsables ante la impotencia del Estado para hacer frente al juego trastornador de las relaciones de poder en la pugna distributiva.

Como quiera que fuere, las concepciones fundamentales del liberalismo económico que reflejan aquellas enseñanzas se degradan irremisiblemente cuando para llevarlas a la práctica, no siempre con pureza doctrinaria, hay que sacrificar el liberal:smo político.

Uno y otro, sin embargo, surgieron históricamente de la misma vertiente filosófica. El liberalismo político para contrarrestar el abuso y la concentración del poder político, principio que a la luz de la experiencia tha adquiriclo un valor humano inconmensurable, por to que representa en sí mismo y en la convivencia entre los thombres, el liberalismo económico para evitar la concentración de poder económico y el privilegio. Complemento, todo ello, de la concentración del poder politico.

No quiero hablar de los centros sino circunscribirme a la periferia y la especificidad cle su capitalismo. Al prescindir de la estructura social, los economistas neoclásicos han falseado el liberalismo. Pues ignoran ese fenómeno extraño del excedente que se ha introducido subrepticiamente en el sistema profanando sus preclaras virtudes. El excedente y el juego arbitrario de relaciones de poder que lleva a la democracia a devorarse a sî misma. Tál es la perversión de la filosofía primigenia del liberalismo. 
Deciamos más arriba que la supresión del poder sindical $y$ político de la fuerza de trabajo mediante el empleo de la fuerza abre el paso a la sublimación de las ideas neoclásicas. Lo cual no significa que éstas rijan pienamente en la práctica, pues suelen aderezarse según los intereses y sus principios no siempre se siguen con inteligencia o virtuosismo técnico. Al contrario, como que a veces surgen inconcebibiles contradicciones.

¿Pero thasta qué punto podriamos nosotros los desarrollólogos reprochar a quienes cuando emplean la fuerza, caen frecuentemente en los brazos de economistas neoclásicos? /Yo digo con gran franqueza que pesa sobre nosotros una gran responsabilidad, puesto que no hemos sabido presentar otra alternativa compatible con el avance y no el retroceso flagrante clel proceso de clemocratización. No es tal alternativa, para oponerse a ese linaje de liberalismo económico, abolir el mercado y transferir al Estado la propiedacl de los medios cle producción a fin de resolver el problema de la acumulación y la clistribución del ingreso, pues ello trae consigo un régimen político fundamentalmente diferente del liberalismo democrático y su concepción de los derechos thumanos.

No considero alternativa aceptable ciertas combinaciones ideológicas que ignoran o desprecian la necesidad ineludible de un esfuerzo considerable y sostenido de acumulación, así como de una gran disciplina distributiva, para transformar el sistema. La transformación exige claros objetivos y racionalidad para alcanzarla, además de un gran impulso emotivo.

Nos encontramos aquí con otro fenómeno de la propagación icleológica de los centros. Siguen gravitando sobre nosotros las teorias del siglo $\mathrm{x}[\mathrm{x}$ con su falsa pretensión de universalidad, como se expresó al comienzo. $\mathrm{Ni}$ los neoclásicos ni el pensamiento marxiano pudieron imaginar el proceso del capitalismo imitativo de la periferia. Ni hay tampoco referencia alguna a ellos en las abstracciones keynesianas. Trátase, recordémosłos de hechos nuevos, de fenómenos de desarrollo tardio de la periferia en cuya estructura social fundamentalmente distinta de la de los centros, se propagan, bajo la hegemonia de éstos, la técnica, las formas de consumo y otras formas cuiturales, las instituciones, las ideas e ideologias. $\mathrm{Y}$ de todo ello -así como de las relaciones centro-periferia- surgen contradicciones que imprimen al sistema un carácter excluyente y conflictivo, según hemos explicado anteriormente.

El proceso capitalista de la periferia es, pues, muy diferente del capitalismo de los centros y su desarrollo histórico. Exige por consi- 
guiente un esfuerzo original de interpretación teórica sin ia cual no podría abordarse una teoría valedera de la transformación del sistema.

Estoy muy lejos de prescindir del pensaniento de los centros, que contiene elementos muy positivos y son parte importante de la herencia cultural que hemos recibiclo. Pero en esto como en otros as pectos no hemos demostrado aptitudes creadoris aprovechando esa herencia cultural $y$ enriqueciendola. Hemos sido sujetos un tanto pasivos de la propagación de los centros, en parte espontánea y en parte deliberada en la contienda ideológica.

Creo que es posible llegar a una gran. sintesis entre esos elementos. positivos de la herencia del liberalismo económico y la herencia de las teorias socialistas a fin de desenwolver sobre bases sólidas el proceso de democratización.

Hacia ello se orientan mis reflexiones frente a las grandes fallas del capitalismo periférico. $Y$ si bion ésta no es la oportunidad de entrar a fondo en la transformación del sistema, creo pertinente adelantar aquí algunas ideas, pues creo que ellas responden a la inspiración que se ha tenido al invitarme a esta disertación.

- Es a mi juicio ineludible que el Estado tome sobre si la responsabilidad primordial de determinar el ritmo de acumulación y de establecer las modalidades de una disciplina distributiva basada en la equidad. Pero considero que para cumplir esta responsabilidad no es necesario transferir a sus manos los medios productivos. No me preocupan tanto las consecuencias económicas de esta concentración del poder, que por cierto distan mucho de ser alentadoras. Pero sí me preocupan hondamente las consecuencias, o si se quiere, las exigencias politicas, la incompatibilidad de esa concentración económica con principios fundamentales del liberalismo político y de su concepto intherente de valores humanos.

$\mathrm{Mi}$ conclusión es terminante y definitiva. El Estado no necesita socializar los medios productivos ni es conveniente hacerlo. Pero tiene ineludiblemente que socializar el excedente para cumplir aquellos objetivos primordiales.

Pues bien, el Estado tendría que captar el excedente de las empresas cuyas dimensiones sobrepasen ciertos límites y en donde surge la mayor parte de tal excedente y retornarlo en gran parte a las mismas empresas de clonde surge, pero no a sus propietarios, sino a la fuerza de trabajo, difundiendo así colectivamente la propiedad de los medios productivos y distribuyendo asimismo una parte del excedente para corregir gradualmente las disparidades estructurales del presente régimen.

El acrecentamiento del ritmo de acumulación hará posible acentuar el ritmo de absorción de los estratos inferiores y debilitar por 
Lo tanto la tendencia excluyente clel sistema hasta cambiar del todo su signo. Forma ésta de redistribución persistente del ingreso a la que se agregarian medidas directas de mejoramiento de tales estratos.

Compréndese que al elevarse en esta forma la proporción del capital en manos de la fuerza de trabajo, ésta irá aumentando progresixamente su gravitación en la gestión de la empresa. Llegará así un momento en que adquiera la mayoría y los propietarios anteriores hayan perdido su poder en la empresa. La socialización del excedente llevaria, pues, a la gestión independiente de las grandes empresas.

iCaben en esto diferentes fórmulas. Si me inclino por una transición gradual es porque quiero atenuar en lo posible los trastornos de una transición al nuevo sistema $y$ no menoscabar su eficiencia, antes bien estimularla por el mayor ritmo de acumulación y el estímulo de la gestión autonómica. Pero no quiero ser dogmático y no elimino la posibilidad de que las circunstancias obliguen a quemar etapas.

Las consideraciones de eficiencia son de suprema importancia en la transformación. Hay que reconocer que el capitalismo periférico ha venido mejorando su eficiencia en forma a veces notable. Me refiero a su eficiencia económica, pues del punto de vista social es de manifiesta insuficiencia. La transformación tiene que imprimir eficiencia social al nuevo sistema y estimular a la vez la eficiencia económica de las empresas.

Esta consideración nos lleva al problema de las fuerzas del mercado. IP'or lo 'que se expresó en estas páginas, muy lejos está el mercaclo de ser el supremo regulador de la economía. No lo es ni en lo que atañe a la acumulación ni a la distribución. $Y$ no siéndolo, se reflejan en el mercado las grandes fallas del sistema. El mercado carece de horizonte social y también cle horizonte de tiempo, pues no anticipa mi resuelve los graves problemas resultantes de la ambivalencia de la teoria. Pero si se resuelven, como hemos visto, esos problemas, el mercado podrá reflejar la eficiencia social del sistema, además de la eficiencia económica de las empresas.

Pero no se trata solamente de eficiencia. Il mercado tiene una gran. significación política, como ya se dijo. Pues, si se prescinde de él serái forzosa la gestión desde la cúspide del sistema determinando lo que se ha de producir y consumir. Poder considerable que trasciende lo económico para proyectarse en el amplio campo de las actividades humanas.

Lo que acabo de exponer de un modo muy general y sucinto parecería suficiente para comprender el sentido de la sintesis que persigo. En la socialización del excedente, y en la disciplina de acumulación y distribución se recurre a elementos primordiales del socialismo. $Y$ en el juego del mercado $y$ la gestión independiente de las 
empresas por quienes trabajan en su seno, se consagran elementos fundamentales del liberalismo económico.

No deja de ser paradojal que para que un sistema funcione como lo habrian imaginado los economistas neoclásicos, para que Ias fuerzas del mercado adquieran verdadera eficiencia social, además de su eficiencia económica, el Estado tiene que dejar de ser prescinr dente como aquéllos habían imaginado.

Tengo la convicción de que esa combinación cle elementos creará las condiciones para que pucla avanzar y consolidarse el proceso democrático. Pero será indispensable también. Ia transformación institucional del Estado.

No es ésta la oportunidad de entrar en ello. Sólo debo subrayar la necesidad de deslindar las funciones politicas de las funciones técnicas.

La disciplina de acumulación y clistribución exige una difícil y delicada tarea de análisis técnico. Pero las decisiones fundamentales tienen que ser políticas.

Por otro lado, Ia gestión de las empresas es una tarea técnica en su sentido más amplio cuya complejidad aumenta con la evolución tecnológica y la dimensión cle aquéllas. La gestión no puede ser política ni estar sujeta a sanción política sino a la sanción del mercado. Y para que surja del seno mismo de las empresas será indispensable dar adecuada ponderación en las decisiones y la conducción cle las empresas a ejecytivos y técnicos, a administrativos y.obreros, esto es a toda la fuerza de trabajo.

He expresado anteriormente que a los economistas del desarrollo, o más bien dicho los desarrollólogos, nos corresponde el deber indeclinable de ofrecer una alternativa social y políticamente valedera para conjurar la crisis del sistema mediante el consenso político o para salir de ella si se ha llegado al empleo de la fuerza. No basta proclamar la fórmula consabida de " $\mathrm{Ni}$ capitalismo ni socialismo". La negación no lleva a grandes soluciones constructivas. Estas páginas se proponen salir de esta confusión.

Como quiera que fuere, la transición hacia un nuevo sistema será larga, difícil y expuesta a muchas vicisitudes. $Y$ sería insincero si no admitiera que las circunstancias de la realidad pudieran llevar a la necesidad de un poder autoritario basado preferiblemente en el consonso y con claros objetivos. Un poder autoritario coyuntural y no estructural como el poder incontrastable que adquiere el Estado al concentrar en sus manos el poder económico.

Su intensidad y duración dependerá en buena medida de la comprensión y cooperación exterior. De un nuevo orden económico mundial que responda a las exigencias de la transformación.

Si todavía no ha podiclo lograr este nuevo orden, la sociedad de 
consumo, seria ilusorio pensar que los centros se encuentren preparados para cooperar con movimiento transformadores por aquella constelación cle intereses que rodea a las transnacionales. Las transacionales, sin embargo, pueden tener un papel importante en la transformación como han comenzado a tenerlo en el mundo socialista.

El curso de los acontecimientos en la periferia exige un tenaz esfuerzo de persuasión de los centros. PPero antes tendremos que persuadirnos nosotrcis mismos de la necesidad y posibilidad de transformaciones fundanentales.

No será posible hacerlo sin tuna visión de largo alcance que se sobrepongat a las exigencias inmecliatas de los centros y la perifcria. Una visión que ha dejaclo cle ser ilusoria porque la técnica tha demostrado plenamente en los centros su ingente potencialidad para lograr un bienestar humano antes inconcebible, aunque no exento de serias consecuencias.

Es responsabilidad fundamental e indeclinable de la periferia aprovechar esa téonica y evitar consecuencias adversas cle su ambivalencia. De no malograr sus frutos en la flagrante inequidad del ámbito estrecho del desarrollo.

Y responsabilidad de los centros de cooperar con los paises periféricos en cuanțo deciclan cumplir con su propia responsabilidad.

Dos siglos de creencia pertinaz en las virtudes del juego espontánco de la economía nos han hecho olvidar -en centros y periferiael trasfondo ético de estos grandes problemas. Porque tiene un claro sentido ético la responsabilidad conjugada de transformar el mundo en desarrollo sin sacrificar los valores trascendentales de la cultura occidental. 